\title{
EchoGéo
}

$13 \mid 2010$

Afrique, 50 ans d'indépendance : État et territoires

\section{Le référent zoulou omniprésent}

Frédéric Giraut, Said Boujrouf et Benoît Rey

\section{OpenEdition}

Journals

Édition électronique

URL : https://journals.openedition.org/echogeo/12039

DOI : 10.4000/echogeo.12039

ISSN : 1963-1197

\section{Éditeur}

Pôle de recherche pour l'organisation et la diffusion de l'information géographique (CNRS UMR 8586)

\section{Référence électronique}

Frédéric Giraut, Said Boujrouf et Benoît Rey, "Le référent zoulou omniprésent », EchoGéo [En ligne], 13 | 2010, mis en ligne le 20 septembre 2010, consulté le 03 août 2021. URL : http:// journals.openedition.org/echogeo/12039; DOI : https://doi.org/10.4000/echogeo.12039

Ce document a été généré automatiquement le 3 août 2021

EchoGéo est mis à disposition selon les termes de la licence Creative Commons Attribution - Pas d'Utilisation Commerciale - Pas de Modification 4.0 International (CC BY-NC-ND) 


\title{
Le référent zoulou omniprésent
}

\author{
Frédéric Giraut, Said Boujrouf et Benoît Rey
}

Illustration 1 - Ephémère mémorial à la gloire de Shaka sur la plage de Durban

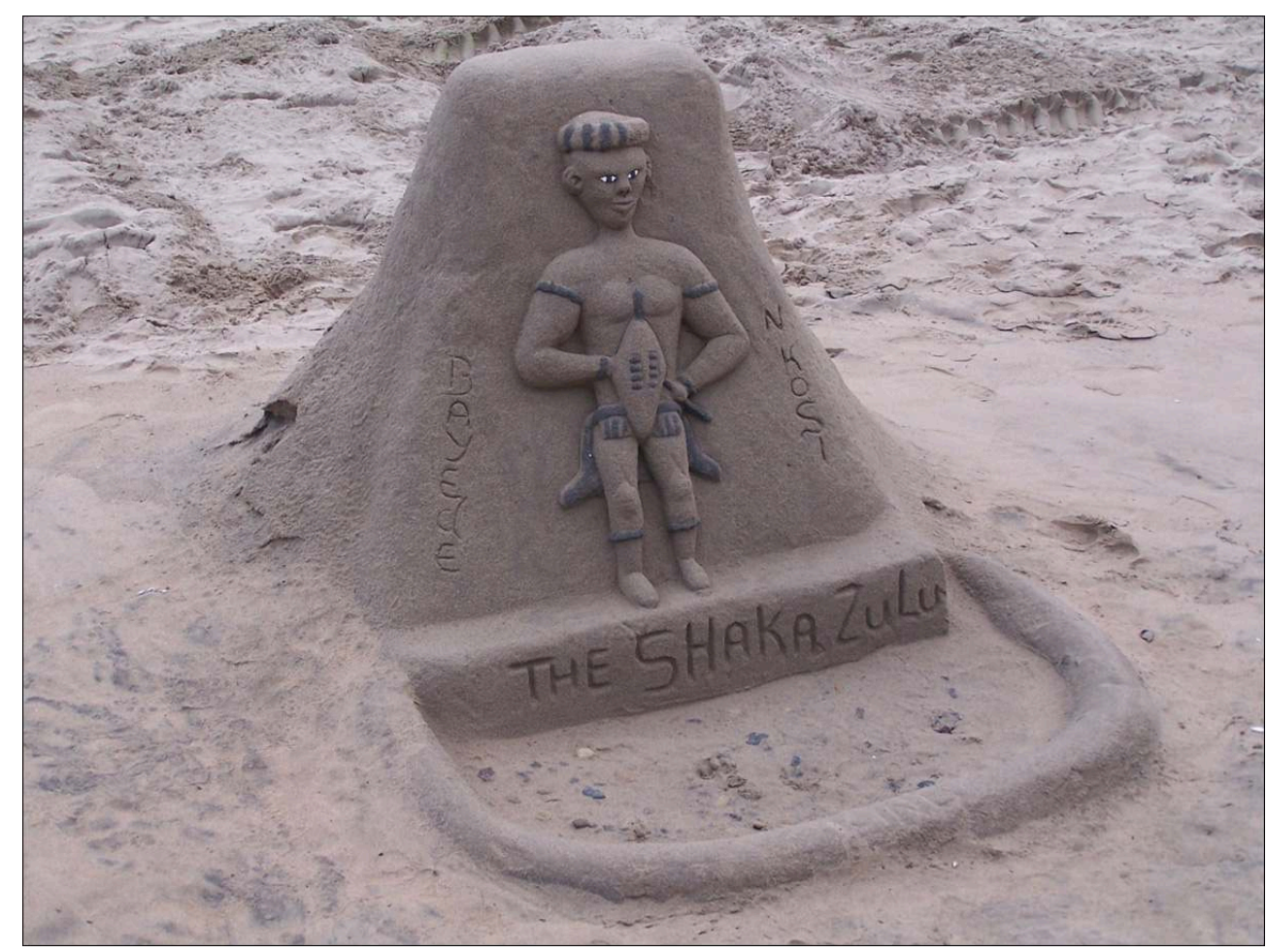

Auteur : Said Boujrouf, Durban, octobre 2007.

En tant qu'épopée d'un royaume précolonial conquérant et éphémère vainqueur de l'armée coloniale britannique, l'histoire zouloue avec son mythique chef Shaka a été érigée en mythe par les colonisés d'Afrique australe et par les colons britanniques et afrikaners. L'histoire guerrière a été mise scène de différents points de vue et à travers différents médias (cinéma, télé, littérature, bande dessinée, parc d'attraction etc.). Elle a pu incarner une certaine résistance à l'oppression coloniale puis d'apartheid ou au 
contraire servir de caution au régime ségrégationniste qui favorisait le mouvement politique ethno-régionaliste Inkhata à la tête du Bantoustan zoulou.

2 Dans l'Afrique du Sud contemporaine, le référent zoulou est omniprésent. Sur le terrain politique, le nouveau président Jacob Zuma cultive cette appartenance en la mettant en scène de manière spectaculaire. Sur le terrain culturel, la référence aux Zoulous est utilisée pour la promotion de l'African Renaissance et des valeurs d'Ubuntu. La cité de Durban y a également recours dans sa stratégie de ville globale, pour revendiquer un ancrage régional prestigieux. Sur le terrain touristique enfin, le KwaZulu-Natal rebaptisé Royaume Zoulou est promu comme destination de nature, balnéaire et d'authenticité africaine. Le pays zoulou est ainsi assimilé à la faune sauvage et aux cités balnéaires de l'océan Indien autant qu'aux aspects ethnoculturels.

3 La référence aux Zoulous et l'usage de leur nom mythique enfin sont présents bien au delà de l'Afrique du Sud et notamment en Amérique du Nord dans une contre culture du hip-hop, du reggae, de la peinture et de la bande dessinée qui reprend ses attributs de résistance, d'oppression, de violence et d'authenticité pour évoquer la marginalité, son désespoir et les mythes qui la nourrissent.

4 Les travaux menés sur les redécoupages territoriaux post-apartheid ainsi que ceux sur les conflits toponymiques ou encore ceux sur la gestion du patrimoine naturel ont tous rencontré la question des usages politiques et économiques du référent zoulou comme en témoigne la bibliographie sélective suivante.

\section{BIBLIOGRAPHIE}

Antheaume B. (ed.), 1999. L'Afrique du Sud : recompositions territoriales, problèmes identitaires, migrations de populations et réseaux. L'Espace Géographique, 끈 2 .

Antheaume B. \& Giraut F., 2002. Les marges au cœur de l'innovation territoriale ? Regards croisés sur les confins administratifs (Afrique du Sud, France, Maroc, Niger, Togo ...). Historiens et géographes, HS Congrès de l'UGI de Durban : Regards sur l'Afrique, F. Bart, J. Bonvallot \& R. Pourtier (eds.), p. 39-58.

Antheaume B. \& Giraut F. (eds.), 2005. Le territoire est mort, Vive les territoires! Paris, IRD Editions.

Antheaume B., Giraut F. \& Maharaj B. (eds.), 2003. Territorial restructurings, comparisons and innovations. Proceedings of the French-South African meeting on territorial innovation, http:// iga.ujf-grenoble.fr/teo/Innovation/introduction.htm

Bouillon A., 1999. Transition et logiques territoriales en Afrique du Sud : “ races ”, (im)migrations, territoires et réseaux.L'Espace Géographique, 2, p. 111-125.

Boujrouf S., Antheaume B., Giraut F. \& Landel P.-A., (eds.), 2009. Les territoires à l'épreuve des normes: référents et innovations, Contributions croisées sud-africaines, françaises et marocaines. Marrakech et Grenoble, Université Cadi Ayyad et Revue Montagnes Méditerranéennes.

Darbon D., 1995. Ethnicité et nation en Afrique du Sud. Imageries identitaires et enjeux sociaux. Paris, Karthala-MSHA. 
Deliry-Antheaume E., 2006. Les murs peints de l'Afrique du Sud post-Apartheid. Sociétés et représentations, $\mathrm{n}^{\circ} 2$, p. 121-147.

Geary F. (trad : J.-P. Ricard), 2004. Quand les nations refont l'histoire. L'invention des origines médiévales de l'Europe (The Myth of Nations). Paris, Aubier.

Gervais-Lambony P., 1998. Espaces et identités en Afrique du Sud : deux reconstructions parallèles ou interdépendantes? In L'Afrique du Sud recomposée, P. Gervais-Lambony (ed.), Géographie et Culture, n² 28, p. 3-14.

Giraut F., Guyot S. \& Houssay-Holzschuch M., 2005. La nature, les territoires et le politique en Afrique du Sud. Annales HSS, 60(4), p. 695-717.

Giraut F., Guyot S. \& Houssay-Holzschuch M., 2008. Enjeux de mots : les changements toponymiques sud-africains. L'Espace géographique, $\mathrm{n}^{\circ}$ 2, p. 131-150. http://www.cairn.info/ revue-espace-geographique-2008-2-p-131.htm

Giraut F. \& Maharaj B., 2003. Contested terrains. Cities and towns in post-apartheid boundaries delimitations. Geojournal, 57(1/2), p. 15-27.

Giraut F. \& Vacchiani-Marcuzzo C., 2009. Territories and Urbanisation in South Africa, Atlas and geohistorical information system (DYSTURB). Paris, IRD Editions (Coll. Atlas Numérique). http:// www.cartographie.ird.fr/dysturb.html

Guyot S., 2006. Rivages zoulous. L'environnement au service du politique en Afrique du Sud. Paris, Karthala/Ed de l'IRD.

Houssay-Holzschuch M., 1996. Mythologies territoriales en Afrique du Sud, un essai de géographie culturelle. Paris, Éditions du CNRS, Espaces et Milieux.

Khosa M.M. \& Muthien Y.G. (eds.), 1998. Regionalism in the new South Africa. Pretoria: Ashgate Publishing Cy.

Lafargue F., 1992. Les Zoulous et l'Inkhatha. In Afriques noires/Afriques blanches, Hérodote, $\mathrm{n}^{\circ}$ 65-66, p. 139-151.

Maharaj B. \& Narsiah S., 2005. La nouvelle géographie régionale de l'Afrique du Sud postapartheid. In Le territoire est mort, Vive les territoires! , B. Antheaume \& F. Giraut (eds.), Paris, IRD Editions, p. 79-107.

Polunic J., 1998. Kwazulu, Natal, Kwazulu-Natal : identités ou identité d'une nouvelle province sud-africaine ? Géographie et Culture, $\mathrm{n}^{\circ}$ 28, p. 15-29.

Porteilla R., 1996. Le processus de recomposition de l'Etat sud-Africain et l'empreinte des bantoustans. In La nouvelle Afrique du Sud, Hérodote, n 82-83, p. 79-112.

Ramuntsidela M.R. \& Donaldson R. (eds.), 2001. The Imprint of Bantustans and Transformation. The South African Geographical, vol.83, nำ1.

Rey B., 2006. Zoulou : un référent dans l'air du temps et de l'espace sud-africain? Mémoire Master 2, Université Joseph Fourier , Grenoble.

Salazar P.J., 1989. L'intrigue raciale, essai de critique anthropologique : l'Afrique du Sud. Paris, Méridiens.

Vail L. (ed.), 1989. The Creation of Tribalism in Southern Africa. Londres, J. Currey. 
AUTEURS

FRÉDÉRIC GIRAUT

Université de Genève, Frederic.Giraut@unige.ch

SAID BOUJROUF

Université Cadi Ayyad-Marrakech, boujrouf@yahoo.fr BENOÎT REY

Pacte-Territoires, benoitrey@yahoo.co.uk 